\title{
1 Porous Chitosan Microspheres as Microcarriers for 3D Cell Culture
}

2 Lixia Huang, ${ }^{1+}$ Lin Xiao, ${ }^{1+}$ Abishek Jung Poudel, ${ }^{1}$ Jixiang $\mathrm{Li}^{2},{ }^{2}$ Ping Zhou, ${ }^{3}$ Mario Gauthier, ${ }^{4}$

3 Haiqing Liu, ${ }^{2^{*}}$ Zhihong $\mathrm{Wu}^{5^{*}}$ Guang Yang ${ }^{1^{*}}$

$4 \quad{ }^{1}$ Department of Biomedical Engineering, College of Life Science and Technology, Huazhong

5 University of Science and Technology, 1037 Luoyu Road, Wuhan 430074, China.

$6 \quad{ }^{2}$ Fujian Provincial Key Laboratory of Polymer Materials, College of Material Science and

7 Engineering, Fujian Normal University, 8 Shangsan Road, Fuzhou 350007, China.

$8{ }^{3}$ Institute of Organ Transplantation, Tongji Medical School, Huazhong University of Science

9 and Technology, 13 Hangkong Road, Wuhan 430074, China.

$10{ }^{4}$ Department of Chemistry, University of Waterloo, 200 University Avenue West, Waterloo

11 N2L 3G1, Canada.

$12{ }^{5}$ Department of Orthopaedic Surgery, Peking Union Medical College Hospital, Peking Union

13 Medical College, 1 Shuaifuyuan Road, Beijing 100730, China.

\section{Corresponding Authors}

15 *E-mail: yang_sunny@yahoo.com. Tel: +86 27-87793523. Fax: +86 27-87792265.

16 *E-mail: haiqing.liu@gmail.com. Tel: +86 591-83404938. Fax: +86 591-83404938.

17 *E-mail: wuzh3000@126.com. Tel: +86 10-69154259. Fax: +86 10-69154259.

18 \$These authors contributed equally.

19 
21 ABSTRACT: Highly porous chitosan microspheres (CSM) were prepared through emulsion-

22 based thermally induced phase separation (TIPS) without using toxic crosslinkers and chemical

23 porogenic agents other than ice. The CSM had an average diameter of $\sim 150 \mu \mathrm{m}$ with

24 interconnected pores varying from $20 \sim 50 \mu \mathrm{m}$ in size. Due to their excellent biocompatibility and

25 unique porous structure, high-performance hepatocyte culture in three-dimensional (3D) space

26 was achieved using the CSM as microcarriers, as cell growth also took place within the internal

27 pores of the CSM, besides their external surface, and multidirectional cell-cell interactions were

28 observed. Enhanced cellular activity and functions were obtained with the CSM microcarriers as

29 compared with 2D cell culture. It is believed that these CSM microcarriers provide a promising

30 platform for 3D cell culture in vitro.

31 KEYWORDS: Chitosan, Porous microspheres, Microcarriers, 3D cell culture, Hepatocytes. 
46

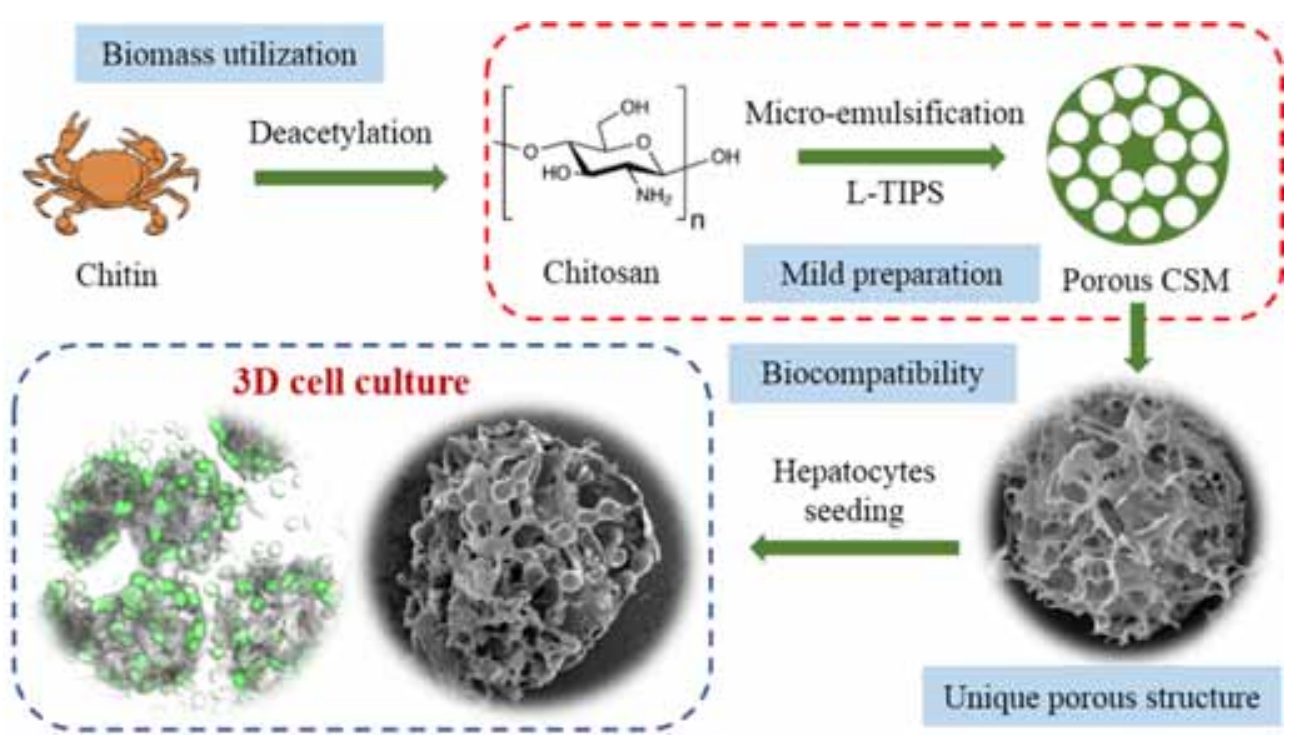

49 Highlights

- CSM were prepared by a mild procedure, free of toxic crosslinking agents and porogens.

51 - The CSM have excellent biocompatibility and a unique porous structure.

52 - Convincing evidence for 3D cell culture was obtained using the CSM as microcarriers.

53 - The CSM microcarriers are favorable to maintaining cellular activity and functions. 


\section{INTRODUCTION}

Traditional cell plate culture has been questioned because of potential changes in

62 morphology and gene expression, often resulting in distortions in cell behavior and biological

63 functions of cultured cells as compared with cells in natural organisms and tissues (Asghar et al.,

64 2015). To better maintain cell morphology, behavior and functions, the concept of three-

65 dimensional (3D) cell culture was proposed, that is cell growth in a 3D environment with

66 sufficient and multidirectional cell-cell interactions mimicking the in vivo architecture of natural

67 organs and tissues (Achilli, Meyer, \& Morgan, 2012; Pampaloni, Reynaud, \& Stelzer, 2007).

68 Natural polymer-based scaffolds have received broad attention for 3D cell culture due to their

69 good biocompatibility and designed structure (Higuchi et al., 2014; Kehr, 2016; Mazza et al.,

70 2015; Motealleh, Hermes, Jose \& Kehr, 2018; Motealleh \& Kehr, 2017; Song et al., 2017). For

71 example, the group of Kehr developed alginate-based 3D hydrogel scaffolds containing periodic

72 mesoporous organosilica or zeolite nanoparticles functionalized with the chiral biopolymers

73 poly(L-lysine) and poly(D-lysine). Chirality-dependent cell adhesion and cell migration were

74 investigated in these hydrogel scaffolds (Kehr, 2016; Motealleh et al., 2017; Motealleh et al., 75 2018).

76 The microcarrier culture technique, first introduced by van Wezel (1967), relies upon 77 microspheres derived from various materials, with either a porous or a non-porous structure, as 78 supports for anchoring cell lines. The main advantages of the microcarrier technology include a 79 high surface area to mass ratio, the use of stirred microcarrier suspension culture, and easy scale80 up making it possible to culture a wide range of animal cells in high yield (Chen, Reuveny, \&

81 Oh, 2013). A wide range of commercial and experimental microcarriers have emerged over the 82 past few decades (Duan et al., 2015; Fang et al., 2014; Healthcare \& Biosciences, 2005; Yu, 
83 Kornmuller, Brown, Hoare, \& Flynn, 2017). However, it should be noted that most of the

84 existing microcarriers only enable cell attachment and growth on their outermost surface, or else

85 on their external pore surface, with either no or only unidirectional cell-cell interactions. This is

86 in essence very similar to monolayer cell culture in plates, and thus may not be considered 3D

87 cell culture in the strict sense. Indeed, real 3D cell culture with microcarriers should enable cell

88 growth within the microcarriers in addition to their surface, with sufficient and multidirectional

89 cell-cell interactions, to mimic more closely the in vivo environment experienced by cells in

90 natural organs and tissues (Achilli et al., 2012). This is considered crucial for the cells to present

91 normal behavior and function. Chung et al. (2008) fabricated amine-functionalized microcarriers

92 with a well-interconnected pore structure from poly(lactic-co-glycolic acid) (PLGA), through

93 gas-promoted foaming in a water-in-oil-in-water double emulsion, for cell cultivation and

94 injectable delivery. Unfortunately, the seeded cells barely infiltrated the inner pores of these

95 supports but rather attached onto their outer surface for the most part. The authors hypothesized

96 that the highly porous skeletal structure of the microcarriers likely did not provide sufficient

97 anchoring surface area for cell attachment within the interior void spaces. Many other

98 microcarriers were reported that only achieved cell growth on their outer surface (Duan et al.,

99 2015; Yu et al., 2017; Zhang et al., 2018). More recently, Yan et al. (2018) reported porous

100 microcarriers fabricated from strontium-substituted hydroxyapatite-graft-poly( $\gamma$-benzyl L-

101 glutamate) nanocomposites. The adhesion and infiltration of rabbit adipose-derived stem cells

102 (ADSCs) within the internal cavities of these microcarriers were confirmed by confocal

103 microscopy. It was shown that labeled ADSCs could be detected at $1 / 8,2 / 8,3 / 8$ and $4 / 8$ diameter

104 depths of the microcarriers, which implied that cell attachment and growth were allowed in the

105 innermost regions of these microcarriers. 
The biopolymer chitosan, obtained by the deacetylation of chitin, has been widely applied in

107 the biomedical field because of its non-toxicity and good biodegradability (Anitha et al., 2014;

108 Pellá et al., 2018). Different chitosan-based porous macroscopic scaffolds were developed for 3D

109 cell culture (Tripathi \& Melo, 2015; Westin, Trinca, Zuliani, Coimbra \& Moraes, 2017). As an

110 example, Tripathi et al. (2015) synthesized sponge-like composite agarose-chitosan scaffolds in

111 various forms including monolith and disc shapes. Primary hepatocyte growth and cell-cell

112 interactions within the interconnected pore network of these scaffolds were observed. Chitosan-

113 based microcarriers were also reported for cell culture (Custódio, Cerqueira, Marques, Reis \&

114 Mano, 2015; Tedesco et al., 2018; Wu et al., 2011; Zhang et al., 2018). For example, Zhang et al.

115 (2018) developed chitosan-based microcarriers reinforced with graphene oxide through an acid-

116 dissolution/alkali-precipitation approach. These hybrid microspheres were able to support stem

117 cell expansion, growth and proliferation. Custódio et al. (2015) also developed chitosan

118 microcarriers, bioconjugated on their surface with monoclonal antibodies favoring cell capture

119 and subsequent cell expansion. Although multiple chitosan-based microcarriers have been

120 investigated over the past decade, there is only one report, by Fang et al. (2014), for which 3D

121 cell culture was supported in the true sense, enabling cell migration to the inside of the carrier

122 and multidirectional cellular interactions. This may be because porous chitosan microspheres are

123 usually prepared by crosslinking emulsions, i.e. chitosan emulsion droplets are first formed, and

124 then stabilized with a crosslinking reagent such as glutaraldehyde. Unfortunately, the pores of

125 chitosan microspheres obtained by that method are not large enough to accommodate cells (Wu

126 et al., 2011). Fang et al. (2014) first prepared porous chitosan microspheres with large pores

$127(47.5 \pm 5.4 \mu \mathrm{m})$ by a phase separation technique. Microcarriers, named PEC, were then

128 fabricated by coating the chitosan microspheres with poly(L-glutamic acid) via electrostatic 
129 interaction and evaluated for cartilage regeneration. The authors confirmed that the poly(L-

130 glutamic acid)-coated PEC microcarriers enabled the proliferation potential of chondrocytes,

131 with cell infiltration and survival in the inner regions of the microcarriers. However they also

132 stated that the poly(L-glutamic acid) modification played a vital role in 3D cell culture, as it

133 enhanced the hydrophilicity of the microcarriers. We previously reported a simple and reliable

134 emulsion-based thermally induced phase separation (TIPS) procedure to fabricate chitosan

135 microspheres with large pores (J. Li et al., 2017). By adapting this preparation method for the

136 current investigation, chitosan microspheres (CSM) with superior biocompatibility and a highly

137 porous structure were obtained and fully characterized. In particular, the suitability of these as-

138 prepared chitosan microspheres as microcarriers for 3D hepatocyte culture was confirmed,

139 without requiring surface modification.

\section{2. Materials and Methods}

\section{2.1. Materials and cell line.}

143 Chitosan (degree of deacetylation $>95 \%$ ) was obtained from Sigma-Aldrich. Its

144 viscosity-average molecular weight, determined with an Ubbelohde viscometer at $25^{\circ} \mathrm{C}$ and the

145 Mark-Houwink-Sakurada equation $[\eta]=\mathrm{KM}^{\alpha}$, where $\mathrm{K}=1.8 \times 10^{-6}$ and $\alpha=0.93$ (Costa,

146 Teixeira, Delpech, Souza, \& Costa, 2015), was $\mathrm{M}_{\mathrm{v}}=1.02 \times 10^{6}$. The surfactants Span 80 (S80)

147 and Tween 60 (T60), acetic acid, petroleum ether and sodium hydroxide $(\mathrm{NaOH})$ were purchased

148 from Shanghai Sinopharm Chemical Reagent Co. Ltd. All the reagents were analytical grade and 149 were used without further purification.

150 A human fetal hepatocyte line, L-02, obtained from Tongji Medical School, Huazhong 151 University of Science and Technology (Wuhan, China) was cultured in RPMI-1640 medium 
152 with $10 \%$ fetal bovine serum and $1 \%$ antibiotics $(100 \mathrm{mg} / \mathrm{mL}$ streptomycin and $100 \mathrm{U} / \mathrm{mL}$ 153 penicillin), by incubation at $37^{\circ} \mathrm{C}$ in a humidified atmosphere containing $5 \% \mathrm{CO}_{2}$.

\section{2.2. Preparation of porous chitosan microspheres (CSM).}

155 To fabricate porous CSM appropriate as 3D culture supports for the L-02 cells, a 156 combination of micro-emulsification and low temperature thermally induced phase separation

157 (L-TIPS) techniques was selected and adapted from the procedure described in our previous 158 work (J. Li et al., 2017). Specifically, a 1\% (w/v) aqueous chitosan solution was prepared by 159 dissolving chitosan powder into $1 \%(\mathrm{w} / \mathrm{v})$ aqueous acetic acid solution (ca. $0.167 \mathrm{M})$, to serve as 160 the dispersed phase. The continuous phase was petroleum ether containing S80 and T60 161 emulsifiers in a mass ratio (S80/T60) of 4.8/0.2, and a total mass content of $5 \%(\mathrm{w} / \mathrm{v})$. The 162 chitosan solution $(10 \mathrm{~mL})$ was added drop-wise into $50 \mathrm{~mL}$ of the continuous phase at $40^{\circ} \mathrm{C}$ 163 under magnetic stirring at $1000 \mathrm{rpm}$ to obtain a w/o emulsion. After stirring for $3 \mathrm{~h}$, the emulsion 164 was quenched and stored at $-20^{\circ} \mathrm{C}$ for $3.5 \mathrm{~h}$. A phase inversion liquid, in the form of $100 \mathrm{~mL} 1 \%$ $165(\mathrm{w} / \mathrm{v}) \mathrm{NaOH}$ solution in ethanol and water $(14: 1, \mathrm{v} / \mathrm{v})$, was then poured into the quenched 166 emulsion under mild stirring. The chitosan microspheres that formed were collected by 167 centrifugation and were successively washed with water and ethanol until the supernatant 168 became neutral, before drying under vacuum at $30^{\circ} \mathrm{C}$. The as-prepared CS microspheres are 169 identified as CSM (Scheme 1).

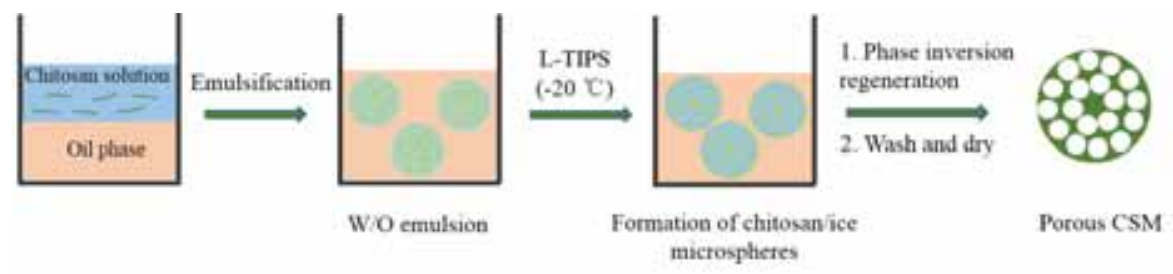

171 Scheme 1. Fabrication procedure for the porous chitosan microspheres (CSM). 


\subsection{Characterization of the CSM.}

173

174 (Quanta 200, FEI) at an accelerating voltage of $20.0 \mathrm{kV}$ after sputter-coating with gold. To

175 characterize the distribution of pores within the particles, the cross-sectional morphology of the

176 CSM was visualized as follows. The CSM were first stained with $1 \%(\mathrm{w} / \mathrm{v})$ Rhodamine B

177 solution in ethanol. After vacuum drying at $30^{\circ} \mathrm{C}$ for $10 \mathrm{~h}$, they were embedded in paraffin and 178 cut into $5 \mu \mathrm{m}$ thick slices on a microtome (Leica RM2235). The cross-section structure was then

179 observed on an Olympus BX51 optical microscope. The specific surface area was characterized 180 by nitrogen adsorption-desorption isotherm analysis at $77 \mathrm{~K}$ (Micromeritics ASAP 2020 181 apparatus). Other physical properties that were characterized include the porosity, pore size 182 distribution, density, water absorption capacity and the elastic modulus. The protocols for these 183 studies are provided in the Supplementary Information.

\subsection{Biocompatibility assay.}

The contact cytotoxicity and non-contact cytotoxicity of the CSM were evaluated with L02 cells. Blood compatibility assays were also performed for the CSM through determination of the hemolysis rate. The specific protocols used for these studies are provided in the Supplementary Information.

\subsection{Cell attachment on/in the CSM.}

A CSM suspension in water $(4 \mathrm{mg} / \mathrm{mL})$, sterilized by autoclaving, was added to a L-02 cell suspension in culture medium $\left(1 \times 10^{5}\right.$ cells $\left./ \mathrm{mL}\right)$ in a volume ratio of $1: 1$. After gentle mixing on a shaker for $1 \mathrm{~h}$, the cell/CSM suspension was transferred to a 24 -well plate at $1 \mathrm{~mL} /$ well. After incubation for $10 \mathrm{~h}$ the cells were washed with PBS three times, followed by progressive 
194 dehydration in $30 \%, 50 \%, 70 \%, 90 \%, 95 \%$ and $100 \%$ ethanol for 10 min each. After freeze-

195 drying, the samples were carefully removed with forceps and placed on conductive adhesive tape

196 on a platform for SEM (SU8010, Hitachi) observation after sputter-coating with gold. The

197 fractured surface of the CSM/cell complex was also obtained and imaged by SEM after the same

198 pretreatment. To determine the cell distribution within the CSM, the cells were stained with

199 Calcein-AM $(2 \mu \mathrm{M})$ and observed by laser scanning confocal microscopy (Olympus FV1000, 200 Japan) at different depths of the CSM after incubation for $48 \mathrm{~h}$.

\section{2.6. Cell activity evaluation.}

The viability of cells cultured on the CSM microcarriers was assessed using a live/dead assay kit (Dojindo, Japan). The L-02 cells were cultured with $2 \mathrm{mg} / \mathrm{mL}$ of CSM in a $35 \mathrm{~mm}$

204 confocal dish (In Vitro Scientific, USA) for 12, 24, 48 or $72 \mathrm{~h}$, respectively. Working solutions

205 of Calcein-AM $(2 \mu \mathrm{M})$ and PI $(4 \mu \mathrm{M})$ were prepared from stock solutions. After washing the 206 cells with PBS solution three times, an equimolar mixture of dyes was added at $500 \mu \mathrm{L} / \mathrm{well}$.

207 After incubation at $37^{\circ} \mathrm{C}$ for $30 \mathrm{~min}$, the samples were observed by laser scanning confocal 208 microscopy (Nikon A1, Japan) using an excitation wavelength of $490 \mathrm{~nm}$ and the green emission 209 at $515 \mathrm{~nm}$ to observe the live cells, while an excitation wavelength of $535 \mathrm{~nm}$ and the red 210 emission at $615 \mathrm{~nm}$ were used to observe the dead cells. To further evaluate cell activity, the cell 211 shape was determined by laser scanning confocal microscopy (Olympus FV1000, Japan) after

212 incubation with the CSM for $48 \mathrm{~h}$. The cell nuclei and cell membranes were stained with

213 Hoechst 33258 (Beyotime, China) $(10 \mu \mathrm{g} / \mathrm{mL})$ and Dil (Beyotime, China) $(10 \mu \mathrm{M})$, respectively.

214 An excitation wavelength of $405 \mathrm{~nm}$ and the blue emission were used to observe the cell nuclei, 215 while an excitation wavelength of $559 \mathrm{~nm}$ and the red emission served to observe the cell 216 membranes. 
The concentration of albumin (ALB) and urea in the culture medium was determined by

219 the competitive enzyme linked immunosorbent assay (ELISA). The cell culture supernatants

220 were collected in a sterile tube after centrifugation for $20 \mathrm{~min}$ at $2000 \mathrm{rpm}$. Aliquots of standards

221 and diluted supernatants $(100 \mu \mathrm{L}$ each) were added to the antibody-coated wells. After

222 incubation for $1 \mathrm{~h}$, the wells were washed three times and incubated with ALB antibody labeled

223 with horseradish peroxidase (HRP) for $1 \mathrm{~h}$. After washing three times, 3,3',5,5'-

224 tetramethylbenzidine (TMB) substrate solution was added before incubation in the dark for 30

$225 \mathrm{~min}$. The OD values were measured spectrophotometrically at $450 \mathrm{~nm}$. The concentration of

226 ALB in the samples was determined by comparing the OD values for the samples to a standard

227 curve.

\section{2.8. Gene expression.}

229 Total RNA extraction from the L-02 cells was achieved with a RNApure Tissue \& Cell 230 Kit (CWBIO, China), after the cells were cultured with $2 \mathrm{mg} / \mathrm{mL}$ of CSM for $48 \mathrm{~h}$ in a 6 -well

231 plate at a seeding density of $30 \times 10^{4}$ cells $/$ well. The total RNA was adjusted to $1.0 \mu \mathrm{g} / \mathrm{sample}$ 232 before it was transcribed into cDNA with a Frist Strand cDNA Synthesis Kit (TOYOBO, Japan)

233 according to the instructions. Fluorescence-based quantitative PCR was conducted using a 7500

234 Fast Real-time PCR system (Applied Biosystems, USA) and SYBR Select Master Mix (Applied 235 Biosystems, USA) according to the manufacturers' guidelines. The specific quantitative primers 236 were synthesized by BGI (Shenzhen, China) with sequences as follows:

237 GAPDH: 5'- ACAACTTTGGTATCGTGGAAGG-3'(sense) and 5'-

238 GCCATCACGCCACAGTTTC-3'(antisense); 
240 GGAAGGTGGGGTCGAAAGG-3'(antisense);

241 GST: 5'-AACCTCAACTGAACAGCATCC-3'(sense) and 5'-

242 GGTTGGTCTTGGTCCTCCTAT-3'(antisense);

243 MRP: 5'-AAGGAGGTACTAGGTGGGCTT-3'(sense) and 5'-

244 CCAGTAGGACCCTTCGAGC-3'(antisense);

245 ASS1: 5'-TCCGTGGTTCTGGCCTACA-3'(sense) and 5'-GGCTTCCTCGAAGTCTTCCTT246 3'(antisense).

\section{2.9. Proteomics analysis.}

248 The cells were lysed and total protein extraction was achieved by the same treatment 249 described above. The protein concentration was determined by the Bradford protein assay. Then 250 the samples were thermally denatured, reduced and alkylated prior to trypsin (Progmega) 251 digestion for $15 \mathrm{~h}$. The digested proteins were labelled with an iTRAQ reagent kit (8 plex, 252 Applied Biosystems) according to the protocol supplied. The fractionated peptide mixtures were 253 analyzed on a Q-Exactive mass spectrometer equipped with an EASY-nLC 1000 System 254 (Thermo Fisher Scientific). The parameters for the spray voltage, capillary temperature and 255 declustering potential of the source ionization were set at $2.1 \mathrm{kV}, 250^{\circ} \mathrm{C}$ and $100 \mathrm{~V}$, 256 respectively.

\section{2.10. Western blot analysis.}

258 For western blot analysis, equal amounts of proteins (20 $\mu \mathrm{g} / \mathrm{sample})$ were separated on 259 SDS-PAGE and transferred onto a PVDF membrane. After blocking overnight, the membrane 260 was successively incubated with primary antibody and HRP-conjugate secondary antibody at 
$26137^{\circ} \mathrm{C}$ for $1 \mathrm{~h}$ with shaking. The bands were visualized using Pierce ECL Western Blotting

262 (Thermo Scientific, USA).

263 2.11. Statistical analysis.

264 Quantitative data are expressed as the arithmetic mean value \pm standard deviation (SD).

265 All the quantitative results were obtained from at least triplicate samples. A t-test was used to

266 detect differences between groups, with $\mathrm{p}<0.05$ considered statistically significant and $\mathrm{p}<$

2670.001 considered highly statistically significant.

\section{3. RESULTS AND DISCUSSION}

\section{3.1. Morphological and physical properties of the CSM.}

The structure of the CSM obtained by the method described is visible in Figure 1. The

271 microspheres have a spherical topology, a diameter of ca. $150 \mu \mathrm{m}$ and a large number of

272 irregular pores varying from 20 to $50 \mu \mathrm{m}$ in diameter (Figure 1A). The pores are interconnected,

273 as can be seen more clearly from the enlarged image section provided in Figure 1B. This was

274 further confirmed by optical microscopy of the microtomed material providing cross-section

275 views of the CSM as exemplified in Figure 1C, likewise revealing the presence of multiple

276 interconnected pores in the $20 \sim 50 \mu \mathrm{m}$ range throughout the whole particles. It was demonstrated

277 in our previous study (J. Li et al., 2017) that such a structure is due to the mechanism of TIPS.

278 Upon quenching the emulsion droplets to $-20^{\circ} \mathrm{C}$, solid-liquid phase separation occurs within

279 them, and the water/acetic acid solvent mixture undergoes slow crystallization allowing the ice

280 crystals to gradually grow larger, leaving behind irregular pores on and within the CSM after the

281 ice crystals are removed. It was further verified that the pore size in the microspheres could be

282 controlled by adjusting the quenching temperature (Fang et al., 2014; J. Li et al., 2017): The pore 
283 size decreases as the quenching temperature is lowered, because a relatively fast crystallization 284 process produces smaller crystals. TIPS is a well-established method for the preparation of 285 porous materials. Crystalline polymers such as polylactide (PLA) and PLGA are often employed 286 to prepare porous materials by the TIPS technique (Ahmadi, Mordan, Forbes, \& Day, 2011; 287 Nina, Raheleh, \& M., 2015; Zhang \& Ma, 2015), but chitosan-based porous materials have been 288 also obtained by the same approach (J. Li et al., 2017; Tripathi et al., 2015).

289 The porosity of the CSM, determined by a liquid displacement method, was as high as $29098.0 \pm 0.5 \%$, which leads to a very low density of $0.040 \pm 0.006 \mathrm{~g} / \mathrm{cm}^{3}$ for the dry CSM. The 291 distribution of pore sizes was also estimated by mercury injection. The results in Figure 1D 292 demonstrate that most pores are within a range of $10 \sim 60 \mu \mathrm{m}$, with an average diameter of 27.8 $293 \mu \mathrm{m}$, which is in good agreement with the SEM observations. The specific surface area was 294 measured to be $30.0 \pm 0.7 \mathrm{~m}^{2} / \mathrm{g}$, much higher than for the commercial Cytopore microcarriers 295 (reported to be 1.0 3.0 m²/g) (Healthcare \& Biosciences, 2005; Ikonomou, Drugmand, Bastin, 296 Schneider, \& Agathos, 2002; Xiao et al., 1999). It is believed that microcarriers with a high 297 specific surface area can provide a large number of anchoring sites for the cells, which is crucial 298 to achieve high density cell culture (Yanagi, Miyoshi, Fukuda, \& Ohshima, 1992). It was indeed 299 suggested that large pores and a high pore interconnectivity within engineered scaffolds promote 300 oxygen/nutrients diffusion, facilitating the in-growth and distribution of cells throughout the 301 constructs (Chiu et al., 2011; Huang et al., 2012). The CSM possess a high water absorption 302 capacity of as much as $2300 \%$, enabling the microcarriers to form stable suspensions in the cell 303 culture medium.

304 Elasticity is one of the most important characteristics of cell microcarriers. On the one hand, it 305 can influence cell behaviors such as differentiation and messenger expression; on the other hand, 
306 sufficient elasticity is required for the microcarriers to withstand shear forces in stirred

307 bioreactors (Cha, Liechty, Khademhosseini, \& Peppas, 2012; K. Li et al., 2004; Radaei,

308 Mashayekhan, \& Vakilian, 2017). The elastic modulus of the CSM measured by atomic force

309 microscopy (AFM) in the wet state was $153 \mathrm{kPa}$ (see Supplementary Information), which is

310 slightly higher than for Cytopore microcarriers. Elastic modulus analysis for soft microspheres

311 was also conducted by other researchers using AFM. For instance, Radaei et al. (2017) measured

312 elastic modulus values of $34 \sim 133 \mathrm{kPa}$ for gelatin/chitosan blend microspheres, depending on

313 their composition.
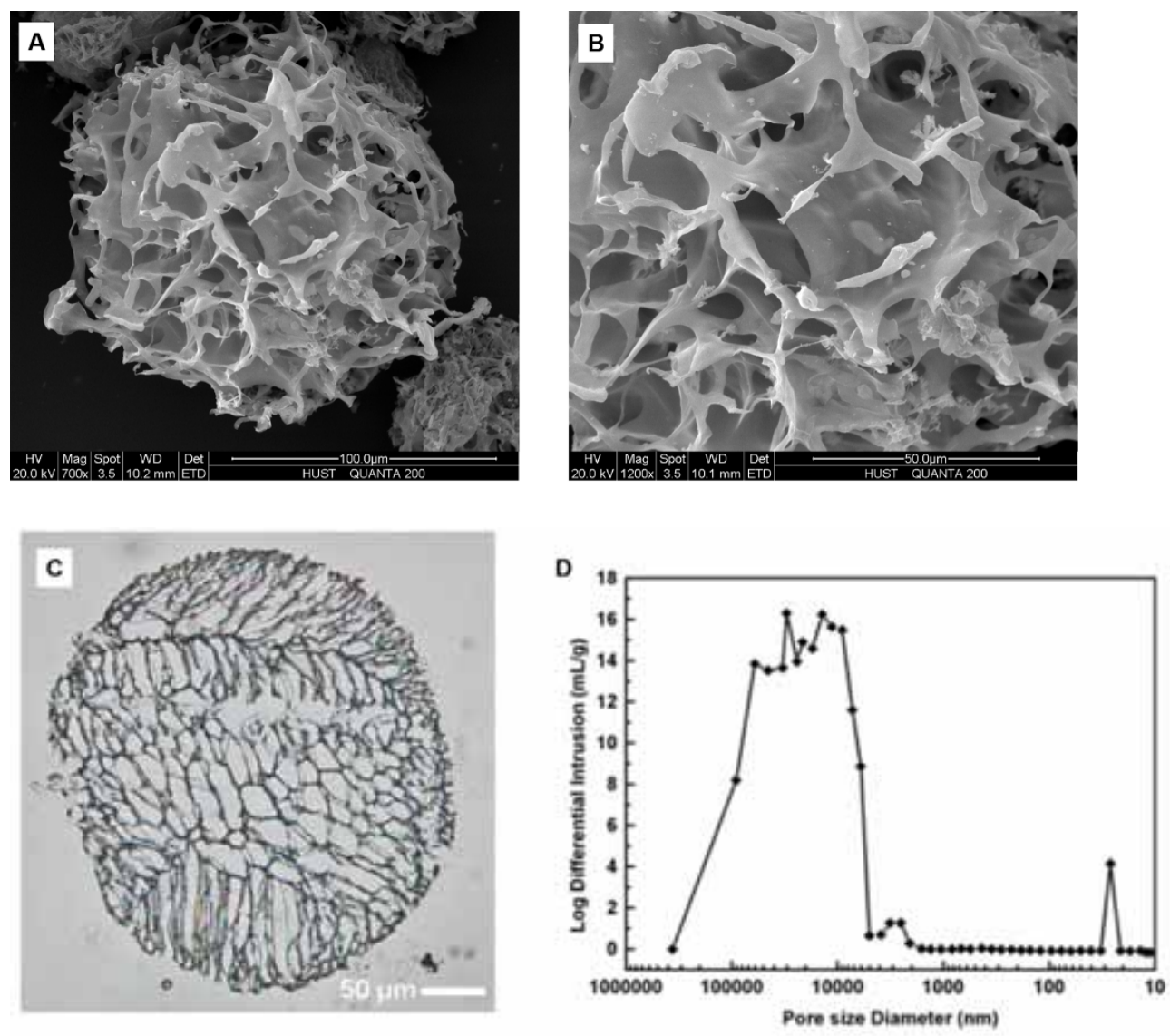

315 Figure 1. Structural and physical properties of the CSM: (A) SEM image; (B) Enlarged section

316 of SEM image; (C) Optical microscopy image for a cross-section view; (D) Pore size 317 distribution. 
318 When the CSM are applied as microcarriers for cell culture, the highly porous structures with

319 interconnected pores, mainly within a size range of $20 \sim 50 \mu \mathrm{m}$, are expected to provide a large

320 surface area for cell attachment and a good 3D environment for cell in-growth. Their elasticity

321 should allow them to remain intact under shear, in addition to supporting the cells. Moreover, the

322 CSM preparation is free of toxic crosslinking agents (such as glutaraldehyde) and porogens

323 (other than ice), making the CSM microcarriers totally toxin-free in composition, which is

324 favorable for growth in cell cultures. Consequently, these as-prepared microcarriers were

325 expected to have a good performance in 3D cell culture.

\subsection{Cytotoxicity and blood compatibility.}

The in vitro cytotoxicity of the CSM to L-02 cells was studied using the CCK-8 assay, and the results obtained are provided in Figure 2 . The viability of L-02 cells incubated with CSM extract (non-contact; Figure 2A) and CSM suspensions (contact; Figure 2B) displayed no

331 significant change at all the concentrations tested, with cell viability over $100 \%$ in all cases.

332 Moreover, it is noted that the viability of L-02 cells incubated with the CSM was higher than for

333 cells incubated with the CSM extract, which suggests that the CSM provided good anchorage

334 facilitating cell adhesion, growth and proliferation. The blood compatibility of the CSM was

335 evaluated by the hemolysis test (Figure 2C). It can be seen that the hemolysis rate with CSM at

336 different concentrations $(0.5,1$ and $2 \mathrm{mg} / \mathrm{mL})$ was ca. $0.14 \%, 0.70 \%$ and $1.07 \%$, respectively.

337 According to standard ASTM-F/756-08 (2000), a hemolysis rate $<2 \%$ is defined as non-

338 hemolytic (Seyfert, Biehl, \& Schenk, 2002). The CSM are therefore considered non-hemolytic

339 over the concentration range investigated. The trend of increasing hemolysis rate with CSM

340 concentration is ascribed to the positive surface charges on the CSM, which could interact 
341 electrostatically with the red blood cells. These superior cell and blood compatibility results 342 indicate that the CSM are highly biocompatible and suitable for biomedical applications 343 involving cell and blood contact.
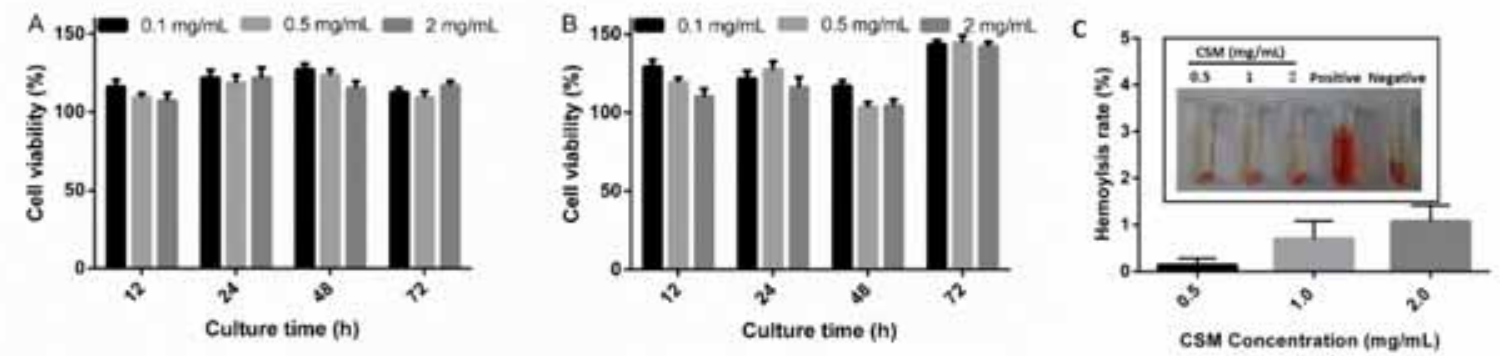

345

346 347

Figure 2. Biocompatibility evaluation: (A) Non-contact and (B) contact cytotoxicity of the CSM by CCK-8 assay with L-02 cells; (C) Hemolysis test for the CSM at different concentrations.

\subsection{Hepatocyte culture with the CSM microcarriers and evaluation.}

SEM images for L-02 cells incubated with the CSM microcarriers for $10 \mathrm{~h}$ are shown in Figures $3 \mathrm{~A} \sim \mathrm{C}$. It is clear that the L-02 cells (indicated by the red arrows) were attached and grew within the internal pores of the microcarriers, in addition to the outermost surface and the external pore surface (Figure 3A). Multidirectional cell-cell interactions were established and extracellular matrix seems to be visible surrounding the cells (Figures 3B, C), suggesting that the cells adapted rapidly to the new environment in the CSM microcarriers and remained in good condition. The fractured surface of a CSM seeded with L-02 cells and incubated for $10 \mathrm{~h}$ was also imaged by SEM; it is presented in the Supplementary Information (Figure S2). It is clearly seen that cells are distributed across the whole fractured surface of the CSM, in addition to the edge. This indicates that cells were able to grow within the internal pores of the CSM, in addition to their external surface. To further confirm cell in-growth within the microcarriers, cell cultures 
360 with the microcarriers were investigated by confocal microscopy after incubation for $48 \mathrm{~h}$. As

361 shown in Figures 3D F, Calcein-AM labeled cells (green) were detected at different depths

362 within the microcarrier from $25 \mu \mathrm{m}$ to $75 \mu \mathrm{m}$. This indicates without any doubt that the cells

363 were able to infiltrate and grow within the inner pores of the CSM.
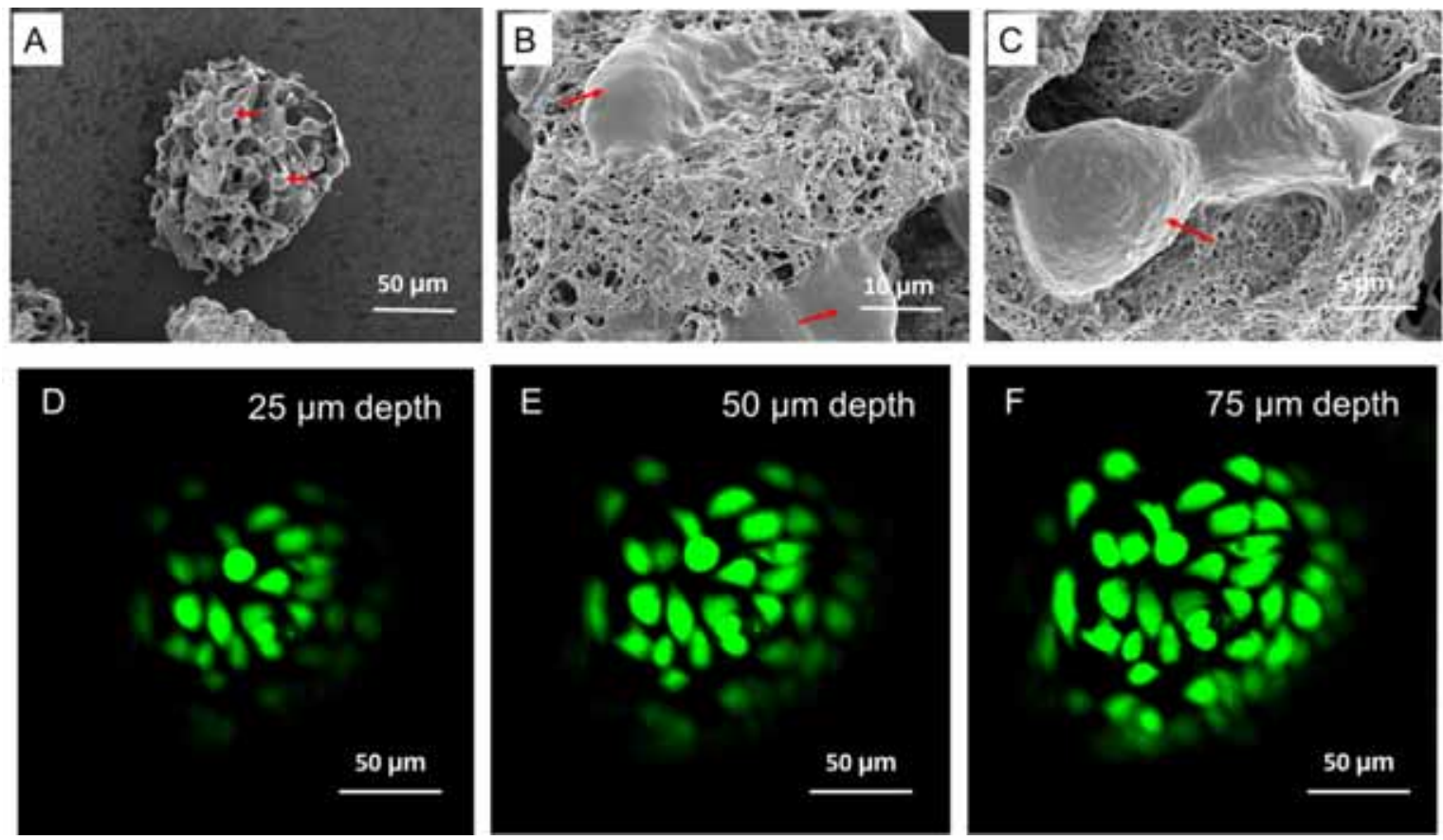

365 Figure 3. Hepatocyte culture with the CSM microcarriers: A C. SEM images confirming the 366 attachment and growth of L-02 cells on/in the CSM microcarriers after incubation for $10 \mathrm{~h}$. The

367 red arrows indicate L-02 cells; D F. Confocal microscopic images showing cell infiltration and 368 growth at depths of 25,50 , and $75 \mu \mathrm{m}$ within the microcarriers after incubation for $48 \mathrm{~h}$.

369 To evaluate cell activity, the Live/Dead assay was used to monitor the growth and proliferation 370 of L-02 cells on/in the CSM microcarriers. Confocal laser scanning microscopy images for L-02 371 cells with specific live-dead staining after $12,24,48$ or $72 \mathrm{~h}$ of incubation with the microcarriers 372 are provided in Figure 4. The live cells were stained with Calcein-AM (green), while the dead 373 cells were stained with Propidium Iodide (PI) (red). It can be seen that the cells incubated with 
374 the microcarriers were highly active, with dead cells hardly observed over the time interval

375 studied. The cell number in the microcarriers increased with time from 12 to $72 \mathrm{~h}$, as reflected in

376 the increased green fluorescence. These results clearly indicate that the CSM microcarriers can

377 support cell survival and proliferation. To further examine cell activity, the cell shape was

378 determined after incubation with the CSM for $48 \mathrm{~h}$, by staining the cell nuclei and membranes

379 with Hoechst 33258 and DiI, respectively. As shown in Figure 5, the L-02 cells exhibited an

380 epithelial-like morphology, which implies the cells had good growth and proliferation status (Hu

381 et al., 2013).

382 The success of the 3D cell culture achieved with the CSM microcarriers is attributed to their

383 unique porous structure, with interconnected pores of $20 \sim 50 \mu \mathrm{m}$, in addition to the good

384 biocompatibility of chitosan, both of which promote good cell adhesion, growth and

385 multidirectional cell-cell interactions. It was indeed suggested that a porous structure plays a

386 vital role in cell culture, because it promotes not only the adhesion, migration and distribution of

387 cells, but also for the exchange of nutrients and metabolic waste (Choi, Xie, \& Xia, 2009). To

388 achieve high-performance cell culture with porous microcarriers or scaffolds, the pore size

389 should fall within an appropriate range (Murphy, Haugh, \& O'Brien, 2010; O’Brien, Harley,

390 Yannas, \& Gibson, 2005; Yannas, Lee, Orgill, Skrabut, \& Murphy, 1989). If the pore size is too

391 small, cell migration is limited, resulting in the formation of a cellular capsule around the

392 microcarriers. Conversely, if the pore size is too large, there is a decrease in surface area limiting

393 cell adhesion (Murphy et al., 2010). The optimal pore size can vary from tens to hundreds of

394 microns for different cell lines, however (O’Brien et al., 2005; Yannas et al., 1989). The pores

395 should also be interconnected to allow sufficient multidirectional cell-cell interactions within the

396 microcarriers. 


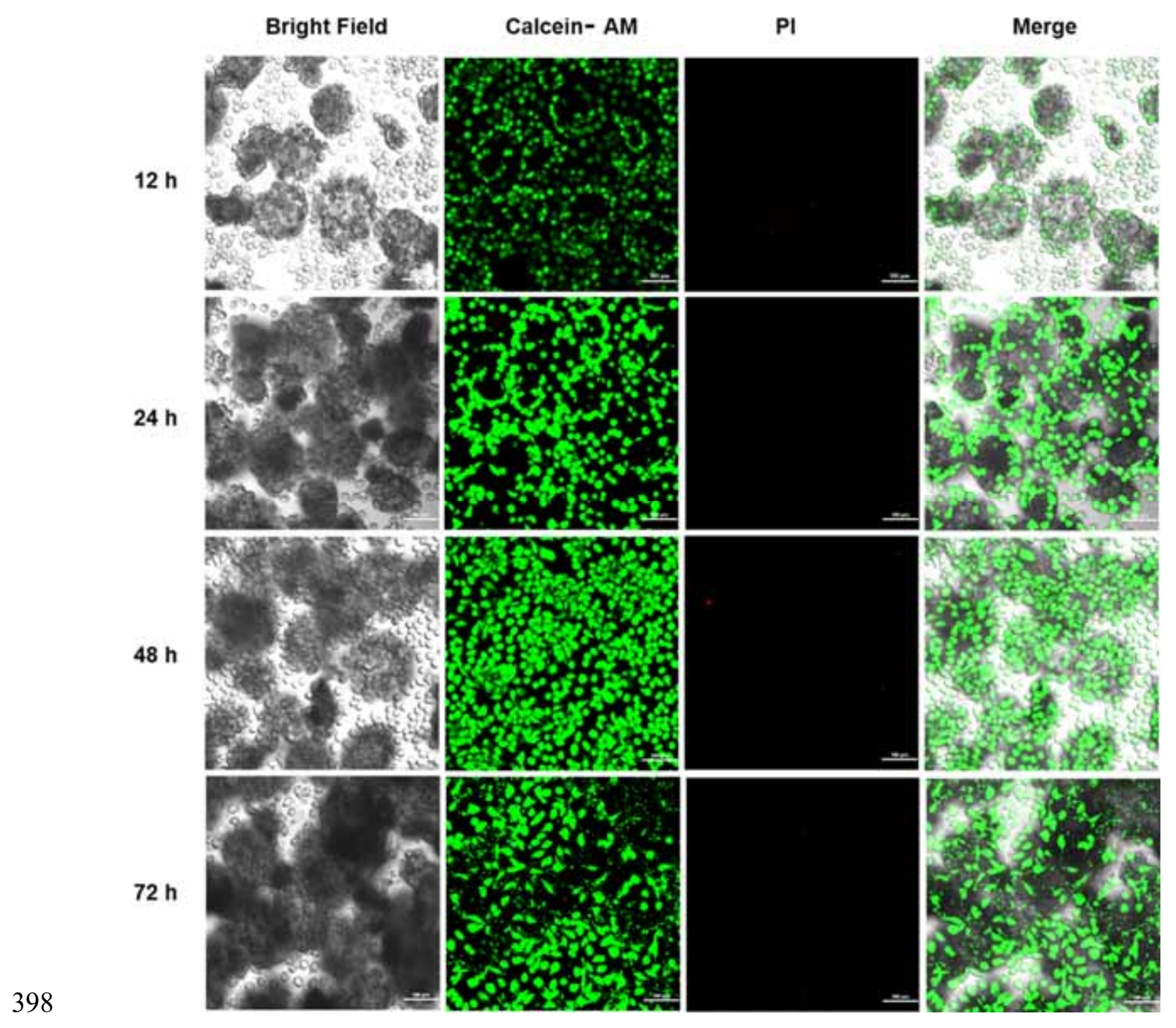

399 Figure 4. Confocal laser scanning microscopy images for L-02 cells after 12, 24, 48 and $72 \mathrm{~h}$ of 400 incubation with the CSM microcarriers. Scale bar: $100 \mu \mathrm{m}$. 

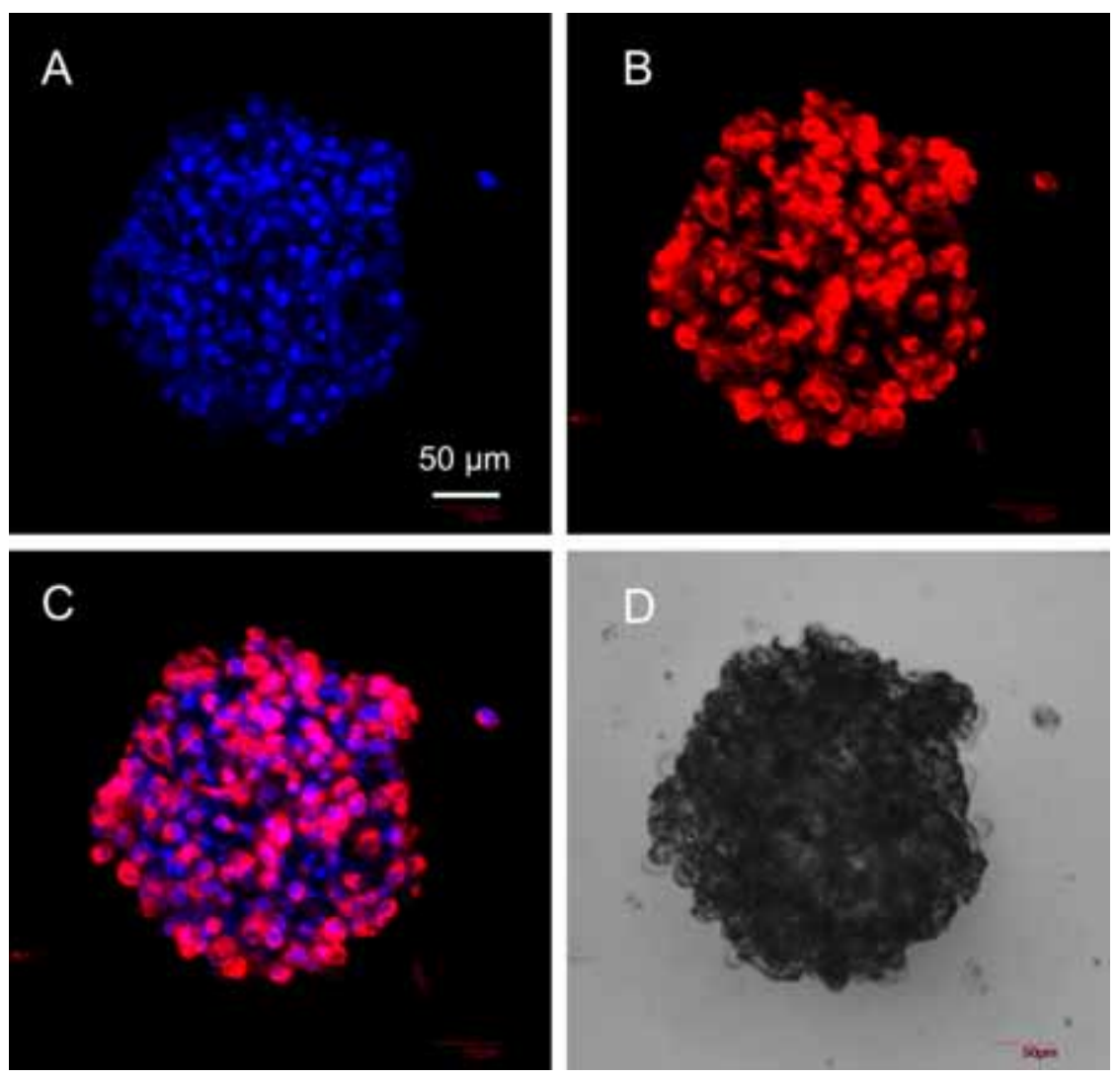

403 Figure 5. Cellular morphology observation by confocal microscopy after incubation with the

404 CSM microcarriers for 48 h: A. Cell nuclei stained with Hoechst 33258; B. Cell membranes

405 stained with DiI; C. Merged image of A and B; D. Bright field image. Scale bar: $50 \mu \mathrm{m}$.

\subsection{Liver function investigation.}

The mRNA expression of liver function-related genes including CYP2E1

409 (cytochromeP450, family2, subfamilyE, polypeptide1), GST (glutathione-S-transferase), MRP

410 (multidrug resistance-related proteins) and ASS1 (argininosuccinate synthase 1) was investigated

411 in L-02 cells cultured with the CSM microcarriers for $48 \mathrm{~h}$. As can be seen in Figure 6A, the

412 mRNA expression levels for the above genes in the CSM-cultured L-02 cells were not

413 significantly different from L-02 cells not exposed to the microcarriers. This indicates that the 
414 CSM microcarriers had no negative effects on the expression of liver function-related genes in 415 the L-02 cells.

416 The expression of proteins related to liver functions in L-02 cells cultured on the CSM 417 microcarriers was studied by proteomics analysis. The relative quantitative expression of the 418 liver function-related proteins OGT1 (UDP glucuronosyl transferase), GST, HGS (hepatocyte 419 growth factor-regulated tyrosine kinase substrate), DHE3 (glutamate dehydrogenase 1, 420 mitochondrial), GPX 1,4 (glutathione peroxidase 1,4) and GSH0 (glutamate-cysteine ligase 421 regulatory subunit 0 ) is depicted in Figure 6B. The results of western blot analysis for MRP and 422 ASS1 are shown in the upper part of Figure 6B. Similarly to gene expression, protein expression 423 related to liver functions in L-02 cells cultured on the CSM microcarriers was almost the same as 424 for L-02 cells not exposed to the microcarriers. This indicates that the CSM microcarriers had no 425 negative effects on the expression of liver function-related proteins in the L-02 cells.

426 To further examine the hepatocellular functions, the albumin secretion and urea synthesis 427 ability were investigated in L-02 cells cultured on the CSM microcarriers. The results, shown in 428 Figure 6C,D, demonstrate that as compared with cells cultured in plates, cells seeded on the 429 CSM produced significantly more albumin each day over the 4-day period investigated, while 430 urea synthesis was also significantly enhanced over the first two days. These results suggest that 431 L-02 cells cultured on the CSM microcarriers had a higher activity than cells cultured in plates, 432 which is probably due to the formation of cell-cell interactions in $3 \mathrm{D}$ space in the former case. 433 With regards to the expression of the different hepatocyte functions, it is known that the 434 establishment of adequate intracellular communication between cells is important (Nakazawa, 435 Izumi, \& Mori, 2009); because the L-02 cells cultured on the CSM microcarriers presumably had 436 better intercellular communication than in the cell monolayers, they may be able to express 
437 higher hepatocyte functions. It is noted that the secretion of albumin and the synthesis of urea 438 decreased over time for cells cultured on both the microcarriers and in plates (Figure 6C,D). 439 Similar results for hepatocyte functions in vitro were reported in the literature (Chua et al., 2005;

440 Seo et al., 2005). For example, Chua et al. (2005) reported hepatocyte culture on galactosylated 441 poly( $\varepsilon$-caprolactone-co-ethyl ethylene phosphate) nanofiber and film scaffolds. They also found 442 that the albumin and urea synthesis functions of the hepatocytes decreased over a 5-day period. 443 However, other studies demonstrated that the hepatocyte functions were maintained or even 444 increased over time (Isoda et al., 2004). This shows the complexity of hepatocyte function 445 maintenance, in that the expression of hepatocyte functions could be influenced by different 446 biochemical and topological cues, among others. 
A
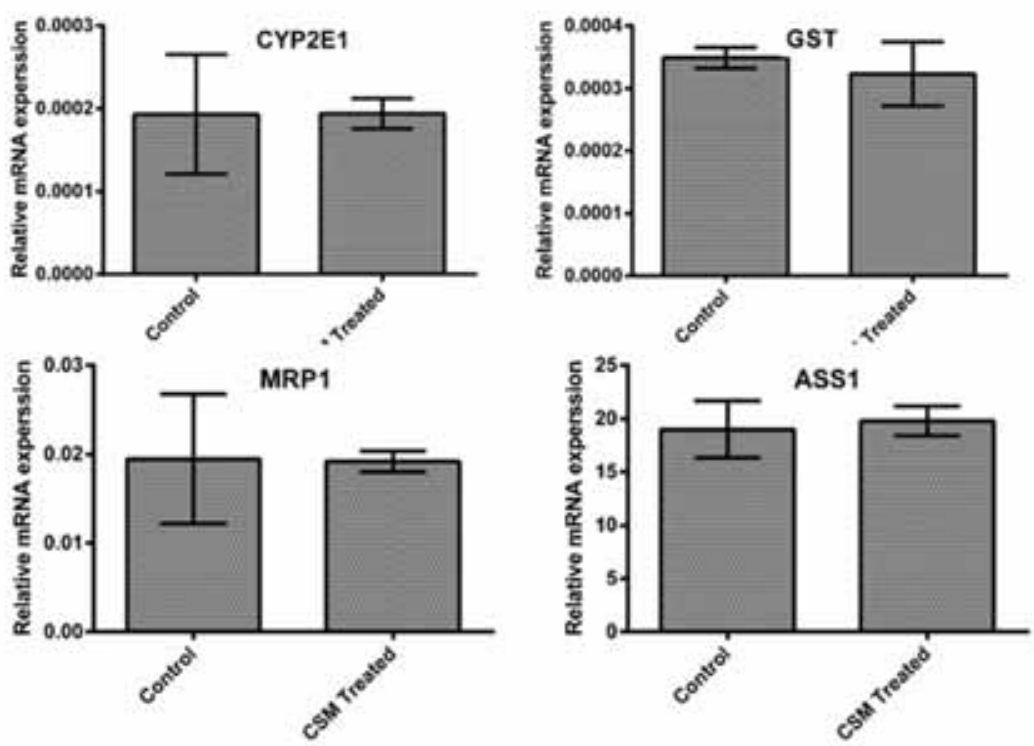

B
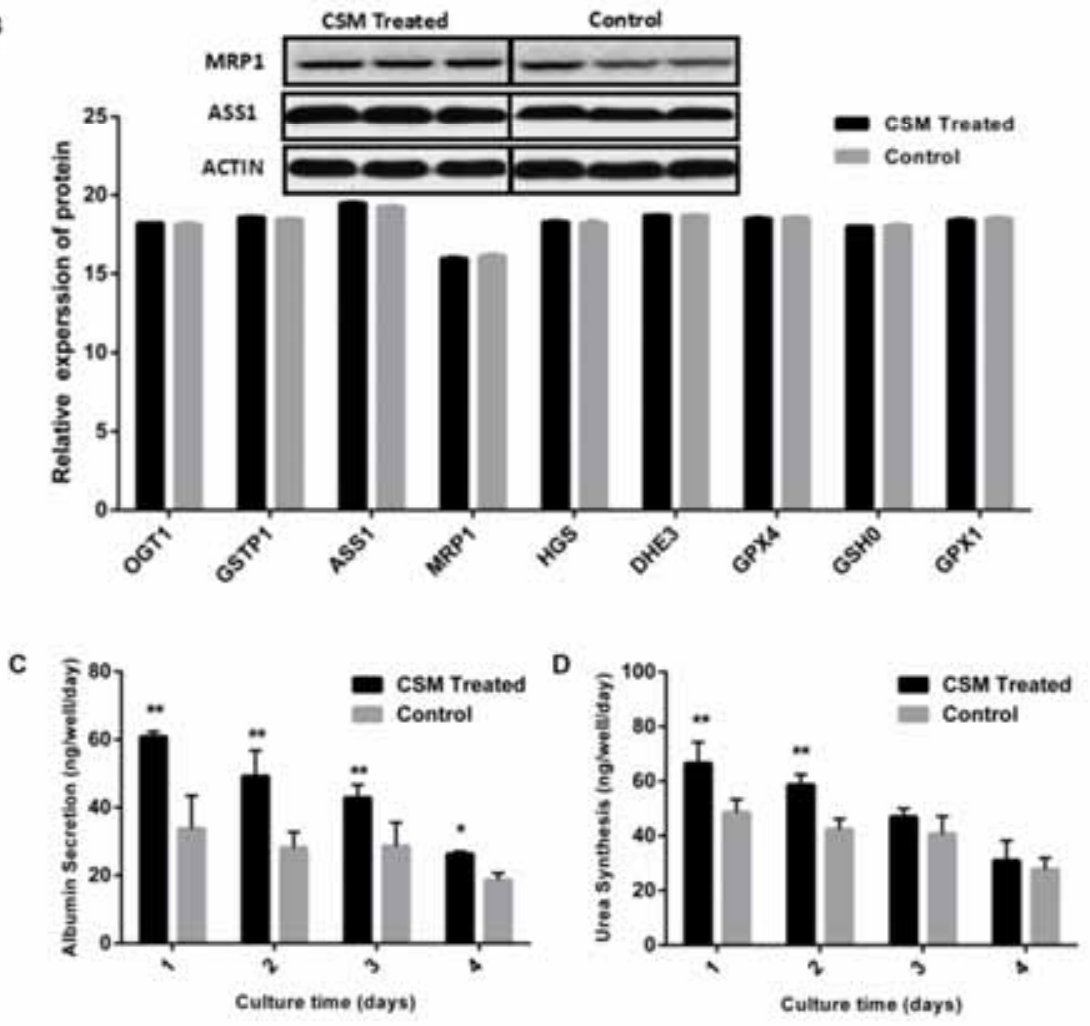

448 Figure 6. Liver function evaluation for L-02 cells cultured with the CSM microcarriers: (A)

449 mRNA expression of liver function-related genes; (B) Liver function-related protein expression;

450 (C) Albumin secretion; (D) Urea synthesis. 


\section{CONCLUSIONS}

Microcarriers based on porous chitosan microspheres (CSM) appropriate for 3D cell

453 culture were developed, by adapting a simple emulsion-based thermally induced phase

454 separation (TIPS) process to produce interconnected pores with a size appropriate to

455 accommodate the cells. The mild preparation conditions used for the CSM, free of toxic reagents,

456 ensured superior biocompatibility of the carriers. 3D cell culture was achieved using these

457 microcarriers with hepatocytes, as cell growth was allowed within the internal pores, in addition

458 to the outermost surface and the external pore surface, and multidirectional cell-cell interactions

459 were observed. These CSM microcarriers are favorable to maintain the activity and functions of

460 the cells in comparison with $2 \mathrm{D}$ cell culture in plates. On the basis of the results obtained, it is

461 believed that these CSM microcarriers have great potential as efficient platforms for 3D cell

462 culture.

\section{ACKNOWLEDGMENT}

465 The authors acknowledge the National Natural Science Foundation of China (General 466 Program, Nos. 21574050 and 21774039), China Postdoctoral Science Foundation (General 467 Program, No. 2015M580640), Science and Technology Support Plan in Jiangsu Province, China 468 (BE2014684) and the independent innovation research funding of Huazhong University of 469 Science and Technology (2014XJGH009) for their financial support. 
473 Supplementary information associated with this article can be found in the online version. The

474 following files are available free of charge: Protocols for the determination of the porosity,

475 density, pore size distribution, water absorption, elastic modulus, and the biocompatibility

476 studies of the CSM, SEM image of a fracture surface of the CSM seeded with L-02 cells

477 (DOCX).

478

479

\section{REFERENCES}

Achilli, T.-M., Meyer, J., \& Morgan, J. R. (2012). Advances in the formation, use and understanding of multi-cellular spheroids. Expert Opinion on Biological Therapy, 12(10), 1347-1360.

Ahmadi, R., Mordan, N., Forbes, A., \& Day, R. M. (2011). Enhanced attachment, growth and migration of smooth muscle cells on microcarriers produced using thermally induced phase separation. Acta Biomaterialia, 7(4), 1542-1549.

Anitha, A., Sowmya, S., Kumar, P. S., Deepthi, S., Chennazhi, K. P., Ehrlich, H., ... \& Jayakumar, R. (2014). Chitin and chitosan in selected biomedical applications. Progress in Polymer Science, 39(9), 1644-1667.

Asghar, W., El Assal, R., Shafiee, H., Pitteri, S., Paulmurugan, R., \& Demirci, U. (2015). Engineering cancer microenvironments for in vitro 3-D tumor models. Materials Today, 18(10), 539-553.

Cha, C., Liechty, W. B., Khademhosseini, A., \& Peppas, N. A. (2012). Designing biomaterials to direct stem cell fate. ACS Nano, 6(11), 9353-9358.

Chen, A. K.-L., Reuveny, S., \& Oh, S. K. W. (2013). Application of human mesenchymal and pluripotent stem cell microcarrier cultures in cellular therapy: Achievements and future direction. Biotechnology Advances, 31(7), 1032-1046.

Chiu, Y.-C., Cheng, M.-H., Engel, H., Kao, S.-W., Larson, J. C., Gupta, S., \& Brey, E. M. (2011). The role of pore size on vascularization and tissue remodeling in PEG hydrogels. Biomaterials, 32(26), 6045-6051.

Choi, S. W., Xie, J., \& Xia, Y. (2009). Chitosan- based inverse opals: Three- dimensional scaffolds with uniform pore structures for cell culture. Advanced Materials, 21(29), 29973001 .

Chua, K.-N., Lim, W.-S., Zhang, P., Lu, H., Wen, J., Ramakrishna, S., . . Mao, H.-Q. (2005). Stable immobilization of rat hepatocyte spheroids on galactosylated nanofiber scaffold. Biomaterials, 26(15), 2537-2547. 
Chung, H. J., Kim, I. K., Kim, T. G., \& Park, T. G. (2008). Highly open porous biodegradable microcarriers: in vitro cultivation of chondrocytes for injectable delivery. Tissue Engineering Part A, 14(5), 607-615.

Costa, C. N., Teixeira, V. G., Delpech, M. C., Souza, J. V. S., \& Costa, M. A. S. (2015). Viscometric study of chitosan solutions in acetic acid/sodium acetate and acetic acid/sodium chloride. Carbohydrate Polymers, 133, 245-250.

Custódio, C. A., Cerqueira, M. T., Marques, A. P., Reis, R. L., \& Mano, J. F. (2015). Cell selective chitosan microparticles as injectable cell carriers for tissue regeneration. Biomaterials, 43, 23-31.

Duan, B., Zheng, X., Xia, Z., Fan, X., Guo, L., Liu, J., . . . Zhang, L. (2015). Highly biocompatible nanofibrous microspheres self-assembled from chitin in $\mathrm{NaOH} / \mathrm{urea}$ aqueous solution as cell carriers. Angewandte Chemie International Edition, 54(17), 5152-5156.

Fang, J., Zhang, Y., Yan, S., Liu, Z., He, S., Cui, L., \& Yin, J. (2014). Poly(1-glutamic acid)/chitosan polyelectrolyte complex porous microspheres as cell microcarriers for cartilage regeneration. Acta Biomaterialia, 10(1), 276-288.

Griffith, C. K., Miller, C., Sainson, R. C. A., Calvert, J. W., Jeon, N. L., Hughes, C. C. W., \& George, S. C. (2005). Diffusion limits of an in vitro thick prevascularized tissue. Tissue Engineering, 11(1-2), 257-266.

Healthcare, G., \& Biosciences, A. (2005). Microcarrier Cell Culture: Principles and Methods: GE Healthcare/Amersham Biosciences.

Higuchi, A., Ling, Q.-D., Kumar, S. S., Munusamy, M., Alarfajj, A. A., Umezawa, A., \& Wu, G.-J. (2014). Design of polymeric materials for culturing human pluripotent stem cells: Progress toward feeder-free and xeno-free culturing. Progress in Polymer Science, 39(7), 1348-1374.

Hollister, S. J. (2005). Porous scaffold design for tissue engineering. Nature Materials, 4, 518.

Huang, C.-C., Wei, H.-J., Yeh, Y.-C., Wang, J.-J., Lin, W.-W., Lee, T.-Y., . . . Sung, H.-W. (2012). Injectable PLGA porous beads cellularized by hAFSCs for cellular cardiomyoplasty. Biomaterials, 33(16), 4069-4077.

Hu, X., Yang, T., Li, C., Zhang, L., Li, M., Huang, W., \& Zhou, P. (2013). Human fetal hepatocyte line, L-02, exhibits good liver function in vitro and in an acute liver failure model. Transplantation proceedings, 45(2), 695-700.

Ikonomou, L., Drugmand, J. C., Bastin, G., Schneider, Y. J., \& Agathos, S. N. (2002). Microcarrier culture of lepidopteran cell lines: Implications for growth and recombinant protein production. Biotechnology Progress, 18(6), 1345-1355.

Isoda, K., Kojima, M., Takeda, M., Higashiyama, S., Kawase, M., \& Yagi, K. (2004). Maintenance of hepatocyte functions by coculture with bone marrow stromal cells. Journal of Bioscience and Bioengineering, 97(5), 343-346.

Kehr, N. S. (2016). Enantiomorphous periodic mesoporous organosilica-based nanocomposite hydrogel scaffolds for cell adhesion and cell enrichment. Biomacromolecules, 17(3), 1117-1122.

Lee, G. Y., Kenny, P. A., Lee, E. H., \& Bissell, M. J. (2007). Three-dimensional culture models of normal and malignant breast epithelial cells. Nature Methods, 4, 359.

Li, J., Wu, X., Wu, Y., Tang, Z., Sun, X., Pan, M., . . . Liu, H. (2017). Porous chitosan microspheres for application as quick in vitro and in vivo hemostat. Materials Science and Engineering: C, 77, 411-419. 
Li, K., Wang, Y., Miao, Z., Xu, D., Tang, Y., \& Feng, M. (2004). Chitosan/gelatin composite microcarrier for hepatocyte culture. Biotechnology Letters, 26(11), 879-883.

Mazza, G., Rombouts, K., Rennie Hall, A., Urbani, L., Vinh Luong, T., Al-Akkad, W., ... Pinzani, M. (2015). Decellularized human liver as a natural 3D-scaffold for liver bioengineering and transplantation. Scientific Reports, 5, 13079.

Motealleh, A., Hermes, H., Jose, J., \& Kehr, N. S. (2018). Chirality-dependent cell adhesion and enrichment in Janus nanocomposite hydrogels. Nanomedicine: Nanotechnology, Biology and Medicine, 14(2), 247-256.

Motealleh, A., \& Kehr, N. S. (2017). Janus nanocomposite hydrogels for chirality-dependent cell adhesion and migration. ACS applied materials \& interfaces, 9(39), 33674-33682.

Murphy, C. M., Haugh, M. G., \& O'Brien, F. J. (2010). The effect of mean pore size on cell attachment, proliferation and migration in collagen-glycosaminoglycan scaffolds for bone tissue engineering. Biomaterials, 31(3), 461-466.

Nakazawa, K., Izumi, Y., \& Mori, R. (2009). Morphological and functional studies of rat hepatocytes on a hydrophobic or hydrophilic polydimethylsiloxane surface. Acta Biomaterialia, 5(2), 613-620.

Nina, P., Raheleh, A., \& M., D. R. (2015). A novel method for differentiation of human mesenchymal stem cells into smooth muscle-like cells on clinically deliverable thermally induced phase separation microspheres. Tissue Engineering Part C: Methods, 21(4), 404412.

O’Brien, F. J., Harley, B. A., Yannas, I. V., \& Gibson, L. J. (2005). The effect of pore size on cell adhesion in collagen-GAG scaffolds. Biomaterials, 26(4), 433-441.

Pampaloni, F., Reynaud, E. G., \& Stelzer, E. H. K. (2007). The third dimension bridges the gap between cell culture and live tissue. Nature Reviews Molecular Cell Biology, 8, 839.

Pellá, M. G., Lima-Tenório, M. K., Tenório-Neto, E. T., Guilherme, M. R., Muniz, E. C., \& Rubira, A. F. (2018). Chitosan-based hydrogels: From preparation to biomedical applications. Carbohydrate polymers, 196, 233-245.

Radaei, P., Mashayekhan, S., \& Vakilian, S. (2017). Modeling and optimization of gelatinchitosan micro-carriers preparation for soft tissue engineering: Using response surface methodology. Materials Science and Engineering: C, 75, 545-553.

Seo, S.-J., Akaike, T., Choi, Y.-J., Shirakawa, M., Kang, I.-K., \& Cho, C.-S. (2005). Alginate microcapsules prepared with xyloglucan as a synthetic extracellular matrix for hepatocyte attachment. Biomaterials, 26(17), 3607-3615.

Seyfert, U. T., Biehl, V., \& Schenk, J. (2002). In vitro hemocompatibility testing of biomaterials according to the ISO 10993-4. Biomolecular Engineering, 19(2), 91-96.

Song, J., Chen, C., Wang, C., Kuang, Y., Li, Y., Jiang, F., . . . Hu, L. (2017). Superflexible wood. ACS Applied Materials \& Interfaces, 9(28), 23520-23527.

Tedesco, M. T., Di Lisa, D., Massobrio, P., Colistra, N., Pesce, M., Catelani, T., ... \& Pastorino, L. (2018). Soft chitosan microbeads scaffold for 3D functional neuronal networks. Biomaterials, 156, 159-171.

Tripathi, A., \& Melo, J. S. (2015). Preparation of a sponge-like biocomposite agarose-chitosan scaffold with primary hepatocytes for establishing an in vitro 3D liver tissue model. RSC Advances, 5(39), 30701-30710.

Van Wezel, A. L. (1967). Growth of cell-strains and primary cells on micro-carriers in homogeneous culture. Nature, 216, 64. 
Westin, C. B., Trinca, R. B., Zuliani, C., Coimbra, I. B., \& Moraes, Â. M. (2017). Differentiation of dental pulp stem cells into chondrocytes upon culture on porous chitosan-xanthan scaffolds in the presence of kartogenin. Materials Science and Engineering: C, 80, 594602.

Wu, X. B., Peng, C. H., Huang, F., Kuang, J., Yu, S. L., Dong, Y. D., \& Han, B. S. (2011). Preparation and characterization of chitosan porous microcarriers for hepatocyte culture. Hepatobiliary \& Pancreatic Diseases International, 10(5), 509-515.

Xiao, C., Huang, Z., Li, W., Hu, X., Qu, W., Gao, L., \& Liu, G. (1999). High density and scaleup cultivation of recombinant $\mathrm{CHO}$ cell line and hybridomas with porous microcarrier Cytopore. Cytotechnology, 30(1), 143-147.

Yan, S., Xia, P., Xu, S., Zhang, K., Li, G., Cui, L., \& Yin, J. (2018). Nanocomposite porous microcarriers based on strontium-substituted HA-g-poly ( $\gamma$-benzyl-1-glutamate) for bone tissue engineering. ACS applied materials \& interfaces, 10(19), 16270-16281.

Yanagi, K., Miyoshi, H., Fukuda, H., \& Ohshima, N. (1992). A packed-bed reactor utilizing porous resin enables high density culture of hepatocytes. Applied Microbiology and Biotechnology, 37(3), 316-320.

Yannas, I. V., Lee, E., Orgill, D. P., Skrabut, E. M., \& Murphy, G. F. (1989). Synthesis and characterization of a model extracellular matrix that induces partial regeneration of adult mammalian skin. Proceedings of the National Academy of Sciences, 86(3), 933-937.

Yu, C., Kornmuller, A., Brown, C., Hoare, T., \& Flynn, L. E. (2017). Decellularized adipose tissue microcarriers as a dynamic culture platform for human adipose-derived stem/stromal cell expansion. Biomaterials, 120, 66-80.

Zhang, S., Ma, B., Wang, S., Duan, J., Qiu, J., Li, D., ... \& Liu, H. (2018). Mass-production of fluorescent chitosan/graphene oxide hybrid microspheres for in vitro 3D expansion of human umbilical cord mesenchymal stem cells. Chemical Engineering Journal, 331, 675684.

Zhang, Z., \& Ma, P. X. (2015). From nanofibrous hollow microspheres to nanofibrous hollow discs and nanofibrous shells. Macromolecular Rapid Communications, 36(19), 17351741. 


\section{Supplementary Information}

\section{Porous Chitosan Microspheres as Microcarriers for 3D Cell Culture}

Lixia Huang, ${ }^{1 \ddagger}$ Lin Xiao, ${ }^{1 \ddagger}$ Abishek Jung Poudel, ${ }^{1}$ Jixiang Li, ${ }^{2}$ Ping Zhou, ${ }^{3}$ Mario Gauthier, ${ }^{4}$ Haiqing Liu, ${ }^{2 *}$ Zhihong $W u, 5^{*}$ Guang Yang ${ }^{1 *}$

${ }^{1}$ Department of Biomedical Engineering, College of Life Science and Technology, Huazhong University of Science and Technology, 1037 Luoyu Road, Wuhan 430074, China.

${ }^{2}$ Fujian Provincial Key Laboratory of Polymer Materials, College of Material Science and Engineering, Fujian Normal University, 8 Shangsan Road, Fuzhou 350007, China.

${ }^{3}$ Institute of Organ Transplantation, Tongji Medical School, Huazhong University of Science and Technology, 13 Hangkong Road, Wuhan 430074, China.

${ }^{4}$ Department of Chemistry, University of Waterloo, 200 University Avenue West, Waterloo N2L 3G1, Canada.

${ }^{5}$ Department of Orthopaedic Surgery, Peking Union Medical College Hospital, Peking Union Medical College, 1 Shuaifuyuan Road, Beijing 100730, China.

\section{Corresponding Authors}

*E-mail: yang_sunny@yahoo.com. Tel: +86 27-87793523. Fax: +86 27-87792265.

*E-mail: haiqing.liu@gmail.com. Tel: +86 591-83404938. Fax: +86 591-83404938.

*E-mail: wuzh3000@126.com. Tel: +86 10-69154259. Fax: +86 10-69154259.

$\ddagger$ These authors contributed equally. 


\section{Porosity and density}

The porosity of the CSM was determined via a liquid displacement method with ethanol as the displacement liquid, as reported in previous studies (Guan, Fujimoto, Sacks, \& Wagner, 2005; Li et al., 2017). Briefly, a certain amount of CSM (Ms) was added to a pycnometer containing absolute ethanol $\left(\mathrm{M}_{1}\right)$. Then the bottle was subjected to low vacuum until the air in the scaffold was completely removed and replaced with ethanol. The bottle was then completely filled with ethanol and was weighed as $\mathrm{M}_{2}$. Then the CSM saturated with ethanol were collected by carefully draining the ethanol, the remaining ethanol on the CSM surface was removed with filter paper. The pycnometer containing wet CSM was weighed as $\mathrm{M}_{3}$. The volume of the CSM was calculated as $V_{S}=\left(M_{1}-M_{2}+M_{3}-M\right) / \rho$ (ethanol). The density $(\rho)$ and porosity $(P)$ were calculated using Equations (S1) and (S2):

$$
\begin{aligned}
& \rho=M_{s} \rho(\text { ethanol }) /\left(M_{1}+M_{3}-M-M_{2}\right) \quad(S 1) \\
& P=V_{P} / V_{S}=\left[\left(M_{3}-M-M_{S}\right) /\left(M_{1}-M_{2}+M_{3}-M\right)\right] \times 100 \%
\end{aligned}
$$

\section{Pore size distribution}

The pore size distribution was estimated with a mercury injection apparatus (AutoPore IV 9500, Micromeritics Instrument Corporation). The equipment operated at pressures of $10 \mathrm{kPa}$ to 300 $\mathrm{MPa}$, to probe pores with diameters ranging from $150 \mu \mathrm{m}$ to $0.005 \mu \mathrm{m}$. The CSM samples were dried with silica gel prior to the measurements. 


\section{Water absorption capacity}

The water absorption capacity of the CSM was investigated as described previously [S1]. A certain amount of dry CSM $\left(\mathrm{M}_{\mathrm{d}}\right)$ was immersed into phosphate-buffered saline (PBS, pH 7.4) solution. The glass beaker containing the mixture was evacuated for $3 \mathrm{~min}$, to allow filling of the pores in the CSM by the solution, and allowed to stand for $24 \mathrm{~h}$. Subsequently, the PBS solution was discarded and excess liquid was removed with filter paper. The mass of the wet CSM (Mw) was measured. Triplicate measurements were made for each sample. The water absorption ratio (A) was calculated using Equation (S3):

$$
\mathrm{A}=\left[\left(\mathrm{M}_{\mathrm{w}}-\mathrm{M}_{\mathrm{d}}\right) / \mathrm{M}_{\mathrm{d}}\right] \times 100 \%
$$

\section{Elastic modulus}

The dry CSM were put into PBS solution and stirred at $400 \mathrm{rpm}$ for $30 \mathrm{~min}$. The elastic modulus (E) of the wet CSM was determined by analysis of the force-displacement curve on an atomic force microscopy (AFM) apparatus. The plot of force versus distance between the probe and the CSM surface was recorded as shown below (Figure S1). The set point was selected as $14 \mathrm{nN}$ for a quadratic pyramid tip and the cantilever was lowered at a velocity of $1 \mu \mathrm{m} / \mathrm{s}$. The constant spring of the cantilever $(\mathrm{Kc})$ was $0.68 \mathrm{~N} / \mathrm{m}$. The local elastic modulus of the sample was calculated using the equations below (Kuznetsova, Starodubtseva, Yegorenkov, Chizhik, \& Zhdanov, 2007; Radaei, Mashayekhan, \& Vakilian, 2017; Hertz, 1881). 


$$
\begin{gathered}
\mathrm{E}=\frac{F}{\pi a^{2}} \\
F=\mathrm{Kc} \times \mathrm{Ks} \times \Delta \mathrm{V}, \text { in which } \mathrm{Ks}=\Delta \mathrm{Z} 1 / \Delta \mathrm{V} 1 \\
\mathrm{a}=\sqrt[3]{\frac{3 \mathrm{FR}}{4 \mathrm{E}}}
\end{gathered}
$$

In these equations, $\mathrm{E}$ is elastic modulus of the CSM; F is the force applied; $a$ is the Hertzian contact radius; $\mathrm{Kc}$ is the constant spring of cantilever (in this study, it was $0.68 \mathrm{~N} / \mathrm{m}$.); Ks is the displacement sensitivity, which is the displacement of the scanner when the operating point changes by one volt. $\mathrm{R}$ is the radius of the CSM tested. Since the values of $\Delta \mathrm{V}, \Delta \mathrm{V}_{1}, \Delta \mathrm{Z}_{1}$ are known for the force curve (Figure S1), the elastic modulus (E) of the CSM can be calculated as $153 \mathrm{kPa}$.

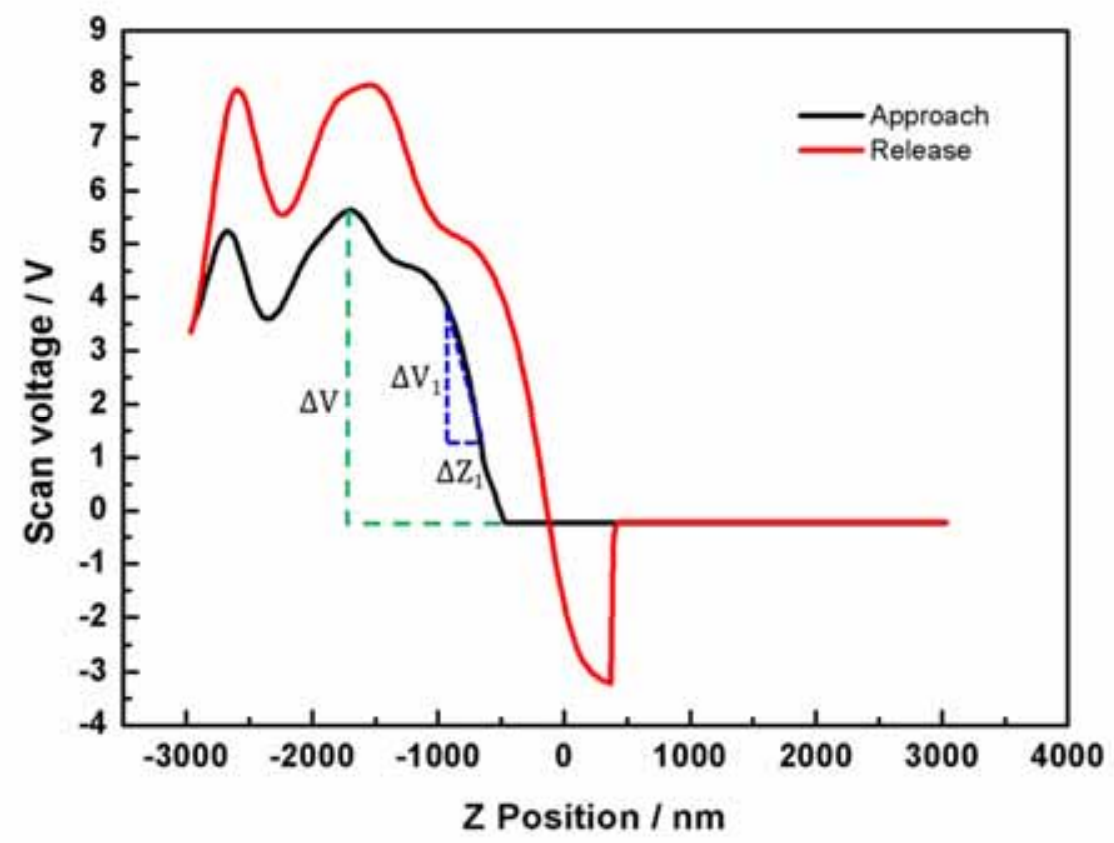

Figure S1. Analysis of the AFM force curve. 


\section{Biocompatibility assay}

Cytotoxicity assay. For the non-contact cytotoxicity assays, a CSM extract was prepared according to ISO 10993-5. Briefly, sterilized CSM were immersed in cell culture medium at different concentrations of $0.5,1.0$ and $2.0 \mathrm{mg} / \mathrm{mL}$ at $37^{\circ} \mathrm{C}$ for $72 \mathrm{~h}$. Solid components were then removed by centrifugation at $10000 \mathrm{rpm}$ for $5 \mathrm{~min}$. The collected supernatant was used as CSM extract after filtration through a $0.22 \mu \mathrm{m}$ filter membrane. The L- 02 cells were seeded at $1 \times 10^{4}$ cells/well in a 96-well plate and incubated at $37{ }^{\circ} \mathrm{C}$ in a $5 \% \mathrm{CO}_{2}$ atmosphere overnight. The medium was then replaced with the CSM extract, using the cell culture medium as control. After incubation for $12,24,48$ or $72 \mathrm{~h}$, the cells were treated with $10 \mu \mathrm{L} /$ well of CCK-8 (Dojindo, Japan) solution with shaking for $5 \mathrm{~min}$ and incubated for another $30 \mathrm{~min}$. Absorbance values were measured in triplicate at $450 \mathrm{~nm}$ using a microplate reader (Multiskan GO, Thermo Fisher, USA). For contact cytotoxicity, the cells were seeded with the CSM at concentrations of $0.5,1.0$ and 2.0 $\mathrm{mg} / \mathrm{mL}$, and the above procedures for the assessment of non-contact cytotoxicity were followed. Cell viability was calculated using Equation (S7), where ODs, ODB and ODN are the OD values for the sample, the blank control and the negative control, respectively.

$$
\text { Cell viability }=\frac{O D_{S}-O D_{B}}{O D_{N}-O D_{B}} \times 10 \% \%
$$

Hemolysis rate test. To evaluate the blood compatibility of the CSM, the hemolysis rate was determined by the method described below. Fresh blood was collected from a healthy rabbit and mixed with heparin immediately to prevent clotting, before dilution with normal saline at a volume ratio of 1:1.25. The CSM samples at different concentrations (i.e. $0.5,1.0$ and $2.0 \mathrm{mg} / \mathrm{mL}$ ) were 
pre-swelled in normal saline overnight. Distilled water and normal saline were used as positive and negative controls, respectively. All the samples $(1.5 \mathrm{~mL})$ were stored at $37^{\circ} \mathrm{C}$ in the presence of $50 \mu \mathrm{L}$ of diluted blood for $30 \mathrm{~min}$. The samples were then centrifuged at $1000 \mathrm{rpm}$ for $5 \mathrm{~min}$ and the supernatant was subjected to absorbance measurements at $545 \mathrm{~nm}$ on a microplate reader (Multiskan GO, Thermo Scientific). The hemolysis rate was calculated using Equation (S8), where $\mathrm{OD}_{\mathrm{s}}, \mathrm{OD}_{\mathrm{N}}$, and $\mathrm{OD}$ a are the absorbance values for the sample, the negative control and the positive control, respectively.

$$
\text { Hemolysis Rate }=\left[\left(O D_{S}-O D_{N}\right) /\left(O D_{P}-O D_{N}\right)\right] \times 100 \%
$$

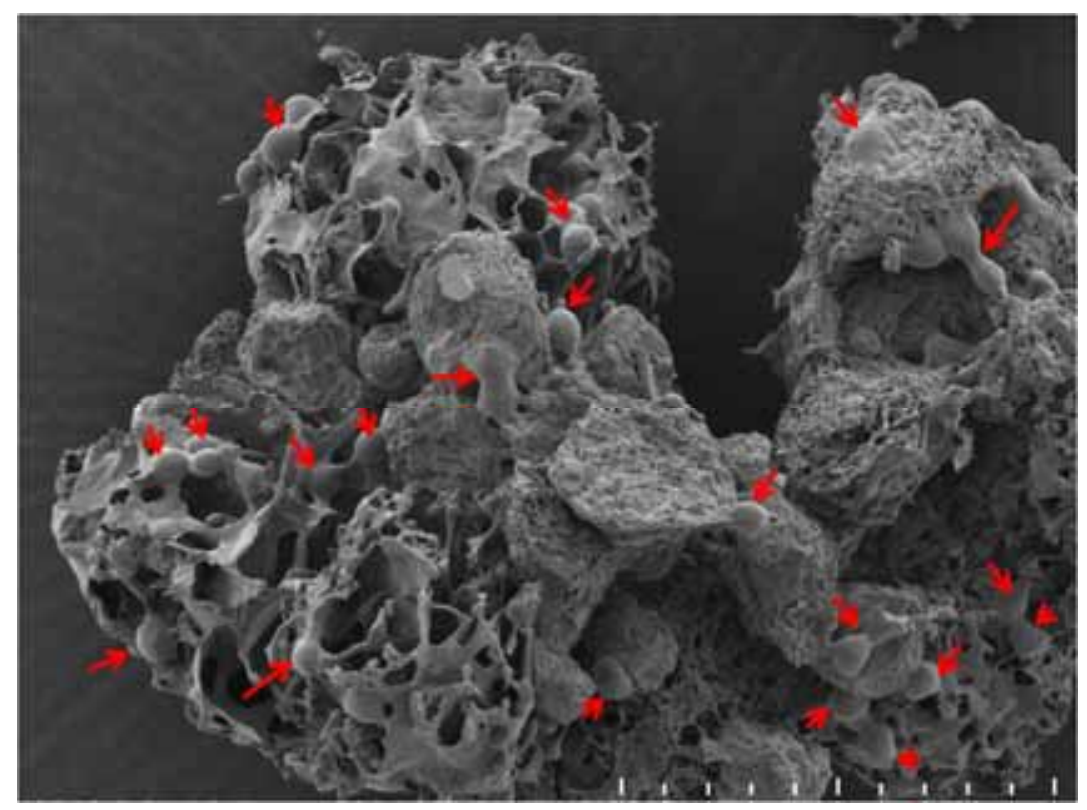

Figure S2 SEM image for a fractured surface of the CSM seeded with L-02 cells (indicated with red arrows) after $10 \mathrm{~h}$ of incubation. Scale bar: $100 \mu \mathrm{m}$. 


\section{References}

Guan, J., Fujimoto, K. L., Sacks, M. S., \& Wagner, W. R. (2005). Preparation and characterization of highly porous, biodegradable polyurethane scaffolds for soft tissue applications. Biomaterials, 26(18), 3961-3971.

Hertz, H. (1881). Ueber den kontakt elastischer koerper. Journal für die reine und angewandte Mathematik. 92, 156-171.

Kuznetsova, T. G., Starodubtseva, M. N., Yegorenkov, N. I., Chizhik, S. A., \& Zhdanov, R. I. (2007). Atomic force microscopy probing of cell elasticity. Micron, 38(8), 824-833.

Li, J., Wu, X., Wu, Y., Tang, Z., Sun, X., Pan, M., . . Liu, H. (2017). Porous chitosan microspheres for application as quick in vitro and in vivo hemostat. Materials Science and Engineering: C, 77, 411-419.

Radaei, P., Mashayekhan, S., \& Vakilian, S. (2017). Modeling and optimization of gelatin-chitosan micro-carriers preparation for soft tissue engineering: Using Response Surface Methodology. Materials Science and Engineering: C, 75, 545-553. 